\begin{tabular}{|c|c|}
\hline & Volume \& Issues Obtainable at The Women University Multan \\
Annals of Social Sciences and Perspective \\
ISSN: 2707-7063, Volume 2, No.1 June 2021
\end{tabular}

\title{
Legal Approaches to Reduce Plastic Marine Pollution: Challenges and Global Governance
}

\author{
Fozia Sarwar', Sajid Ali ${ }^{2}$, Shaukat Hussain Bhatti ${ }^{3}$, Saif ur Rehman ${ }^{4}$
}

${ }^{1}$ Lecturer, Govt. Degree College for Women, Dunyapur, Multan.

${ }^{2}$ Lecturer, School of Economics, Bahauddin Zakariya University, Multan.

${ }^{3}$ Assistant Professor, Department of Law, Times Institute, Multan.

${ }^{4}$ PhD Scholar, School of Economics, Finance and Banking, Universiti Utara, Malaysia.

\begin{tabular}{ll}
\hline \multicolumn{2}{l}{ ARTICLE DETAILS } \\
\hline History: & \\
Received: & March 08, 2021 \\
Review: $\quad$ June 26, 2021 & June 26, 2021 \\
Accepted: $\quad$ Jvailable Online: June 30, 2021
\end{tabular}

\section{Keywords:}

Plastic marine pollution; Global Governance; Legal approaches; International conventions.

\begin{abstract}
Plastic wastes have recently emerged as one of the alarming threats to the marine environment. The issue of contamination of marine plastic is not new; it has been recognized for over half a century. The problem can no longer be ignored, thanks to growing media attention and incidents such as the finding of the Great Pacific Garbage Patch. This issue is addressed by a number of legal approaches. Plastic litter reduction standards were adopted by the International Maritime Organization (IMO) 30 years ago. Annexes to the convention of MARPOL are designed to aid in the fight against plastic pollution. Other mechanisms of maritime law can be used to combat this issue as well. The fundamental cause of the issue, and thus the solution is located on land. The directives of the European Union can serve as useful models for decreasing marine pollution. In May 2018, the new European Union restrictions are proposed to target the ten most commonly detected single-use plastic products in coastal areas of Europe, as well as lost and abandoned fishing gear. These multinational conventions serve as a source of inspiration for the governments of other countries of the world. The acceptance and application of these legal approaches and conventions could change the game in the fight against marine pollution.
\end{abstract}

(C) 2021 The Authors, Published by WUM. This is an Open Access Article under the Creative Common Attribution Non Commercial 4.0

Corresponding author email address: sajidali1136@gmail.com

\section{Introduction}

Plastics are organic synthetic polymers that were mass-produced for the first time in the 1930s and 1940s. The versatility of plastic has resulted in a major increase in its use in many 
aspects of daily life. Because of the extensive use of plastic in the production of single-use items, it accounts for a major amount of global litter, a trend that is much more prominent in the marine environment. Plastic makes up between 50 and 90 percent of marine waste (Haward, 2018). Packaging is the most important market for plastic resins, as it is frequently designed to be thrown away quickly (Plastics Europe, 2018). Plastics are also a significant part of the global economy. With revenue of 355 billion Euros in 2017, the plastic sector directly employs over 1.6 million people in Europe and ranks seventh in terms of the contribution in industrial value-added (Plastics Europe, 2018). A big amount of marine litter is composed of microscopic particles and packaging of unidentified plastics or polystyrene that originates on land (UN Environment, 2017). Litter from ordinary people, industrial pollution, vulnerable landfills, harbors, and dumps along the shore or waterways are examples of these (Galgani et al., 2015). Almost 75\% of plastic pollution in the oceans originates in Asia's growing middle-income countries, such as China, the Philippines, Indonesia, Sri Lanka, and Vietnam, where waste collection systems are incapable of dealing with the big amounts of trash. Rivers are a key marine plastics transit route, with an estimated 1.20 to 2.50 million tones entering the ocean each year.

Plastic marine debris comes from a variety of places. Human activities at sea are a major source of plastic debris in marine environments. Fishing activities result in thousands of tons of plastic fishing gear being dropped into the world's oceans each year (Derraik, 2002). Furthermore, merchant fleets drop or lose a large amount of plastic materials on intentionally or by accident. However, human activity on land is the principal source of plastic trash in the marine environment, which is sadly often unregulated. Land-based polluted items in the marine environment are estimated to account for 80 percent of all marine litter (Haward, 2018). Beachgoers leave large amounts of plastic on the beach, and rivers and drainage systems carry it to the sea. Plastics also wind up in marine seas as a result of inland waste mismanagement, poor trash disposal site preparation and administration, and illegal dumping. Annually, 4.9 to 13.8 million metric tons of plastic are predicted to reach the oceans from 192 coastal countries (Stafford \& Jones, 2019).

\section{Global Legal Approaches and Plastic Marine Pollution}

One of the most crucial sources of international law governing human effect on the marine environment is known as the United Nations Convention on the Law of the Sea (UNCLOS). It defines the definition of marine pollution as "the existence of substances in the marine sea, including estuaries by man that has or is likely to have deleterious effects on marine life or living resources, impediment to marine activities, risks to human health, fishing and other legal uses of the sea". Despite not being primarily an environmental treaty, the convention requires states to take, jointly or individually as reasonable measures consistent with this convention that are required to avoid, minimize, and control contamination of the maritime environment from whatever source" (art. 194 (1)). It also states that "countries should take all necessary measurements to ensure that activities under their control or jurisdiction to not pollute other countries or their environments, and that pollution created from their activities under their control or jurisdiction does not spread beyond the areas over which they have sovereign rights" (art. 194 (2)). Unfortunately, UNCLOS does not go much further than these broad declarations in terms of regulating the problem of marine plastic litter in detail (Nyka, 2019).

Other treaties, on the other hand, clarify the general duties arising from UNCLOS. The London Dumping Convention, which was constituted in 1972, prohibits dumping as a means of introducing plastic waste into the marine environment. It also developed the first 
comprehensive worldwide rule against garbage dumping (Beyerlin \& Marauhn, 2011). This is also the most widely known regulation of dumping at sea, with 87 member states. Dumping is defined in the agreement as the purposeful disposal at sea of garbage or other materials from vessels, platforms, planes, or other man-made structures (art. 1 (a)). Plastics and other synthetic materials, such as ropes and netting that float in the sea and interfere considerably with fishing, shipping, or other lawful uses of the sea are included in Annex I of this dumping convention.

The Protocol to the dumping convention, which was signed in 1996 by the majority of industrialized countries, was also signed by the majority of industrialized countries (51 parties) (entered into force in 2006). The Protocol also decreased the number of exclusions that permitted the dumping of Annex I wastes in specific instances. The Protocol, like the original Convention, uses a reversed listing technique. State parties must ban the dumping of "any wastes or other substances except those indicated in Annex 1." Furthermore, even the trash specified in Annex 1 requires a specific permit from government authorities. The absence of plastic from Annex 1 can be construed as a blanket prohibition on the disposal of plastic garbage (Avery-Gomm, Walker, Mallory, \& Provencher, 2019).

The United Nations Environment Programme (UNEP) has developed a set of proposals to address the issue of marine pollution. The Honolulu Strategy was adopted in 2012. The first goal of this strategy is to reduce the volume and impact of marine trash produced by landbased sources. To achieve this goal, seven initiatives were proposed, including educational initiatives, the usage of market-based instruments, the implementation of best practices and suitable storm water infrastructure, and capacity building, among others (Kandziora et al., 2019). The Global Partnership of Marine Litter is another UNEP project in the issue of marine litter. UNEP passed a non-binding resolution on microplastics and marine litter in 2017 to encourage governments to adopt integrated and source-to-sea measures to address microplastics and marine litter from all sources (Resolution UNEP/EA.3/L.20).

The activities listed above address both land-based and sea-based causes of plastic pollution, but they cannot address plastic manufacturing. Aside from wastewater treatment (SDG-6), marine resources conservation (SDG-14), and the management of waist for sustainable environment in cities (SDG-11), targets for reducing the impacts of dangerous chemicals, water, soil, and air pollution (SDG-3), and sustainable use and production (SDG-4) (Nazar, Meo, \& Ali, 2020). Existing multilateral environmental treaties, such as 'Stockholm Convention on Persistent Organic Pollutants (POPs)' (2004) and the 'Basel Convention on Transboundary Movements of Hazardous Wastes and Their Disposal' (1989), could provide a home for the concept of plastics management. The Basel Convention, signed in 1989, intends to limit hazardous and other waste generation, as well as transboundary transportation, and encourage "near-source" disposal. It provides a legal tool for regulating international plastics trade that can be reinforced in order to reduce the amount of plastic trash produced. The Stockholm Convention was a watershed moment in international law because it addressed persistent organic pollutants. The Stockholm Convention can regulate the production and disposal of additives used in the manufacturing of plastics to some extent; however, this influence would only apply to plastics made with terms and conditions listed in the conventions, and its implementation have consequences for the reuse and recycling of chemical products (Peng et al., 2020). The global action plan of 'Strategic Approach to International Chemicals Management (SAICM)' can be used to supervise chemicals not covered by the Stockholm convention and to help countries set national reduction objectives (UN Environment, 2017). 


\section{Regional Legal Approaches and Plastic Marine Pollution}

Despite UNCLOS' centrality in maritime governance, regional conventions play an essential role as well. In the Caribbean, a regional action plan has been developed for marine litter management. A Northwest Pacific Action Plan has been established to safeguard the maritime environment for the Northwest Pacific Region against land-based activities (Garcia, Fang, \& Lin, 2019). EU law in European Union countries also stressed regional cooperation as a tool for promoting environmental protection objectives not just within the EU, but also among its neighbors. The convention for the Protection of the Marine Environment of the North-East Atlantic, located in northern Europe, established the Regional Action and Implementation Plan (Bishop, Styles, \& Lens, 2020). It developed monitoring and data reporting methods for marine litter. This plan focuses on the welcome facilities on sea-port and fishing gear management, among other things. One of the most modern and innovative regional maritime treaties, the Helsinki Convention for the Protection of the Marine Environment of the Baltic Sea Area (HELCOM), controls environmental protection in the Baltic Sea Region (Kandziora etal., 2019). In 2015, the Baltic Sea Regional Action Plan for Marine Litter was adopted. HELCOM established a regional goal of significantly decreasing marine litter and minimizing litter-related impact in marine and coastal environments by 2025. The Barcelona Convention for the Protection of the Mediterranean Marine Environment and Coastal Region (the Barcelona Convention) addresses pollution originating on land as well as at sea. As part of the Barcelona Convention, parties produced the first legally enforceable plan for marine litter management in Europe, the Regional Plan for Marine Litter Management in the Mediterranean (Fossi et al., 2020).

Regional economic integration organizations also participate in regional projects. The European Union, with its well-developed shared environmental policy, can serve as a model for other regional cooperation initiatives in the field of environmental preservation. The European Union's current 7th Environmental Action Programme addresses the issues of proper waste management and avoiding maritime contamination (Bishop et al., 2020). The European Union's environmental policy is guided by the 7th Environmental Action Programme, which was adopted in 2013 and will last through 2020. The basic goal of the program is to protect, conserve, and improve the EU's natural capital. In response to these political initiatives, legislation was enacted. In 2015, the Packaging Directive was updated. A mandate was introduced to limit the use of lightweight plastic carrier bags, with a maximum of 90 bags per person per year by 2019 and a further reduction to 40 bags per year by 2021 . (art. 4). This demonstrates that the European Union has chosen the most effective way to reducing marine plastic pollution, which is to minimize the manufacturing and consumption of plastic products.

\section{Challenges and Global Governance for Marine Pollution}

Existing struggles to minimize marine plastic pollution are not fruitful due to issues with marine plastic governance. Because of its durability, flexibility of applications and low cost, plastic production has skyrocketed. Plastic has numerous benefits as a durable, lightweight materials that are now ubiquitous in our daily routines and is necessary in the transportation and health sectors. To resolve the issue, however, plastic manufacturing and consumption must be reduced, as well as a more sustainable approach across the entire lifecycle (Ping et al., 2020). Experts, on the other hand, do not recommend just replacing plastic products, as 
this may result in new environmental difficulties. According to them resolving the issue of marine plastic pollution can bring changes in the current economic structure and a reassessment of current behaviors regarding minimization of marine plastic pollution (Haward, 2018; Kandziora et al., 2019; Peng et al., 2020).

All across the world, plastics are created, processed, consumed, and disposed away. Governments and businesses, as well as other government divisions, must collaborate more effectively. Maritime plastic pollution has influence not just on national marine zones, but also on the deep seas, which are outside of national control. As a result, it is a global issue that needs cooperation at international level and it cannot be managed by a few countries alone. There is also a shortage of transparency on the additives and chemicals used in plastic products. Primary plastic additives have the potential to infect recycled plastics, providing a health danger. Transparency is also lacking in terms of plastic waste exports and imports, as well as criteria for acquiring recycling facilities. Transparency of additives and chemical contents in plastic, as well as international movements of plastic wastes are crucial for successful and long-term recycling.

International cooperation is essential to resolve these difficulties, improve production and use of plastic, transition to a circular economy, and limit the amount of plastic waste. International law becomes ineffective when it comes to dealing with land-based causes of marine plastic pollution. Addressing the problem of marine plastic pollution would require substantial coordination in terms of aims, implementation, monitoring, reporting, and compliance procedures within the current frameworks (UN Environment, 2017). Changes to the above-mentioned treaties, according to nongovernmental organizations, are unlikely to ever succeed in avoiding plastic contamination of the sea, and hence a new treaty is required. A deal to tackle marine plastic pollution must have an impact on production cycles of countries and industrial processes, making it both ocean treaties and a convention on sustainable consumption and production (David Suzuki Foundation, 2018). At the moment, no such convention exists, and sea governance and marine plastic pollution controls are primarily studied separately. Some important regions have yet to enact binding agreements to address the problem and a new world mechanism would give long-term legislative security at the national level, ensure uniform rules for all industry competitors, and assist in ensuring fairer compensation and greater liability for those who stand to lose as a result of restrictions (Haward, 2018).

Struggles have been made at the global, national and, regional levels with both legally and voluntary enforceable rules in place to address land-based and sea-based sources, and chemical management individually. However, the issues of marine plastic governance necessitate a solution that takes into account all three dimensions at the same time. A global treaty addressing sea governance and pollution controls could be a solution, as it can tackle the sources of marine plastic pollution both at sea and land, as well as increasing transparency and checks on the use of chemicals in plastic products.

\section{Conclusion}

It's a paradox that creating a comparatively effective system for avoiding pollution from ships was easier than preventing pollution from land-based sources in the fight against marine plastic litter. There are more monitoring options onshore, and it is theoretically easier to control garbage than in or on the water. However, one explanation for this condition is that modern civilization must confront the fact that we are addicted to plastic. Plastic has become one of the most commonly produced materials during the previous six decades, and the 
prescription will be harsh for our consumption habits. Determining a problem does not absolve us of the responsibility to take steps to reduce marine plastic pollution, especially given the importance of marine biodiversity. Regional legislations offer an intriguing model for developing new worldwide laws in the field of marine plastic waste management. Various approaches to the details of the instrument, from the drafting of a new agreement to the inclusion of the question of plastics into an existing legal instrument, such as the UNCLOS, have been proposed, aimed at promoting the conservation and sustainable usage of marine biological diversity in areas beyond the national jurisdiction.

\section{References}

Avery-Gomm, S., Walker, T. R., Mallory, M. L., \& Provencher, J. F. (2019). There is nothing convenient about plastic pollution. Rejoinder to Stafford and Jones "ViewpointOcean plastic pollution: A convenient but distracting truth?". Marine Policy, 106, 103552.

Beyerlin, U., \& Marauhn, T. (2011). International environmental law. Hart, CH Beck, Nomos.

Bishop, G., Styles, D., \& Lens, P. N. (2020). Recycling of European plastic is a pathway for plastic debris in the ocean. Environment International, 142, 105893.

David Suzuki Foundation, 2018. Interview by Lead Author, Name Withheld].

Derraik, J. G. (2002). The pollution of the marine environment by plastic debris: a review. Marine pollution bulletin, 44(9), 842-852.

Fossi, M. C., Vlachogianni, T., Galgani, F., Degli Innocenti, F., Zampetti, G., \& Leone, G. (2020). Assessing and mitigating the harmful effects of plastic pollution: the collective multi-stakeholder driven Euro-Mediterranean response. Ocean \& Coastal Management, 184, 105005.

Galgani, F., Hanke, G., \& Maes, T. (2015). Global distribution, composition and abundance of marine litter. In Marine anthropogenic litter (pp. 29-56). Springer, Cham.

Garcia, B., Fang, M. M., \& Lin, J. (2019). Marine plastic pollution in Asia: All hands on deck!. Chinese Journal of Environmental Law, 3(1), 11-46.

Haward, M. (2018). Plastic pollution of the world's seas and oceans as a contemporary challenge in ocean governance. Nature communications, 9(1), 1-3.

Kandziora, J. H., Van Toulon, N., Sobral, P., Taylor, H. L., Ribbink, A. J., Jambeck, J. R., \& Werner, S. (2019). The important role of marine debris networks to prevent and reduce ocean plastic pollution. Marine pollution bulletin, 141, 657-662.

Nazar, R., Meo, M. S., \& Ali, S. Role of public health and trade for achieving sustainable development goals. Journal of Public Affairs, e2585.

Nyka, M. (2019). Legal approaches to the problem of pollution of marine environment with plastic. Zeszyty Naukowe Akademii Morskiej w Szczecinie.

Peng, G., Bellerby, R., Zhang, F., Sun, X., \& Li, D. (2020). The ocean's ultimate trashcan: Hadal trenches as major depositories for plastic pollution. Water research, 168, 115121.

Plastics Europe. 2018. Plastics - the facts (2018). [accessed on 29-02-2020]. https://www.plasticseurope.org/application/files/6315/4510/9658/Plastics_the facts_2 018_AF_web.pdf

Stafford, R., \& Jones, P. J. (2019). Viewpoint-Ocean plastic pollution: A convenient but distracting truth?. Marine policy, 103, 187-191.

UN Environment, 2017. Combating Marine Plastic Litter and Microplastics: An Assessment of the Effectiveness of Relevant International, Regional and Subregional Governance Strategies and Approaches. 